\title{
Proper use and interpretation of diaphragmatic ultrasonography
}

\author{
Rakesh V. Sondekoppam, MD $\cdot$ Latha Naik, MD $\cdot$ Jenkin Tsui, BSc $\cdot$ \\ Ban C. H. Tsui, MSc, MD
}

Received: 29 December 2016/Revised: 2 January 2017/ Accepted: 9 February 2017/Published online: 17 February 2017

(c) Canadian Anesthesiologists' Society 2017

\section{To the Editor,}

We read with interest the technical description by ElBoghdadly et al. ${ }^{1}$ regarding the utility of ultrasound scanning as part of the assessment of diaphragmatic function after brachial plexus blockade. We are appreciative of their admission regarding the novelty of our previously described $\mathrm{ABCDE}$ plus sniff technique ${ }^{2}$ and their decision to emulate it as part of their attempt "to further simplify diaphragm ultrasonography" by "using simple surface marking". Unfortunately, their description neglects the importance of the systematic "step by step" approach we outlined. They also incorrectly claim that gross caudal movement of the pleural line can reliably be used to detect diaphragmatic paralysis. To appreciate the pros and cons of each approach more fully, however, it is important to show clearly where one technique ends and the other begins.

Although not cited in their article, the basis for our use of the sniff test and El-Boghdadly et al.'s use of surface markings primarily stem from the original concept of the "ABCDE" approach, ${ }^{3}$ a mnemonic aid for locating ideal scanning sites to evaluate the diaphragm via intercostal windows rather than hepatic or splenic windows. It involves placing the ultrasound probe at the (A)nterior

This letter is accompanied by a reply. Please see Can J Anesth 2017; 64: this issue.

R. V. Sondekoppam, MD · L. Naik, MD · J. Tsui, BSc Department of Anesthesiology and Pain Medicine, University of Alberta, Edmonton, AB, Canada

B. C. H. Tsui, MSc, MD (ه)

Department of Anesthesiology, Perioperative and Pain Medicine, Stanford University, Palo Alto, CA, USA

e-mail: bantsui@stanford.edu axillary line just below the level of the nipple, identifying pleural/lung sliding during (B)reathing, and moving the probe in a $(\mathrm{C})$ audal direction along the axillary line until the (D)iaphragm can be identified and (E)valuated. This mnemonic method utilizes step-by-step landmarking of readily recognizable features, such as lung sliding or movement of the pleural line, to locate the diaphragmatic muscle, which is the primary area of interest. It seems that El-Boghdadly et al. intended to describe a new technique of their own by eliminating these systematic steps from the $\mathrm{ABC}$ approach - advocating only probe placement at ribs 78 (right) or ribs 8-9 (left). By following this course, however, they may have unknowingly reported a technique with a starting location similar to that described by Sarwal et $a .^{4}$

More importantly, we question their claim that assessment of diaphragmatic function can be based on the indirect evidence of pleural movement. This approach based on an indirect inference made from pleural movement, rather than direct visualization of changes in diaphragmatic muscle thickness - is not only susceptible to physiological artefacts, it is subject to the variability of the patient's respiratory effort. Generation of tidal volume and associated pleural movement seen on ultrasonography is the net result of the actions of all inspiratory muscle groups, abdominal muscle groups, and rib cage movement. It does not measure the individual contribution of any single muscle group. ${ }^{5}$ Hence, the caudal extent of the pleural line does not necessarily correlate with diaphragmatic function in the setting of either acute (Figure) or chronic paralysis. ${ }^{6}$ Thus, measurement of muscular thickness has been considered to be sensitive and specific for assessing diaphragmatic function. ${ }^{4,6}$

We recently performed a pilot study ${ }^{7}$ that showed that the newly described $\mathrm{ABCDE}$ approach provided easy 

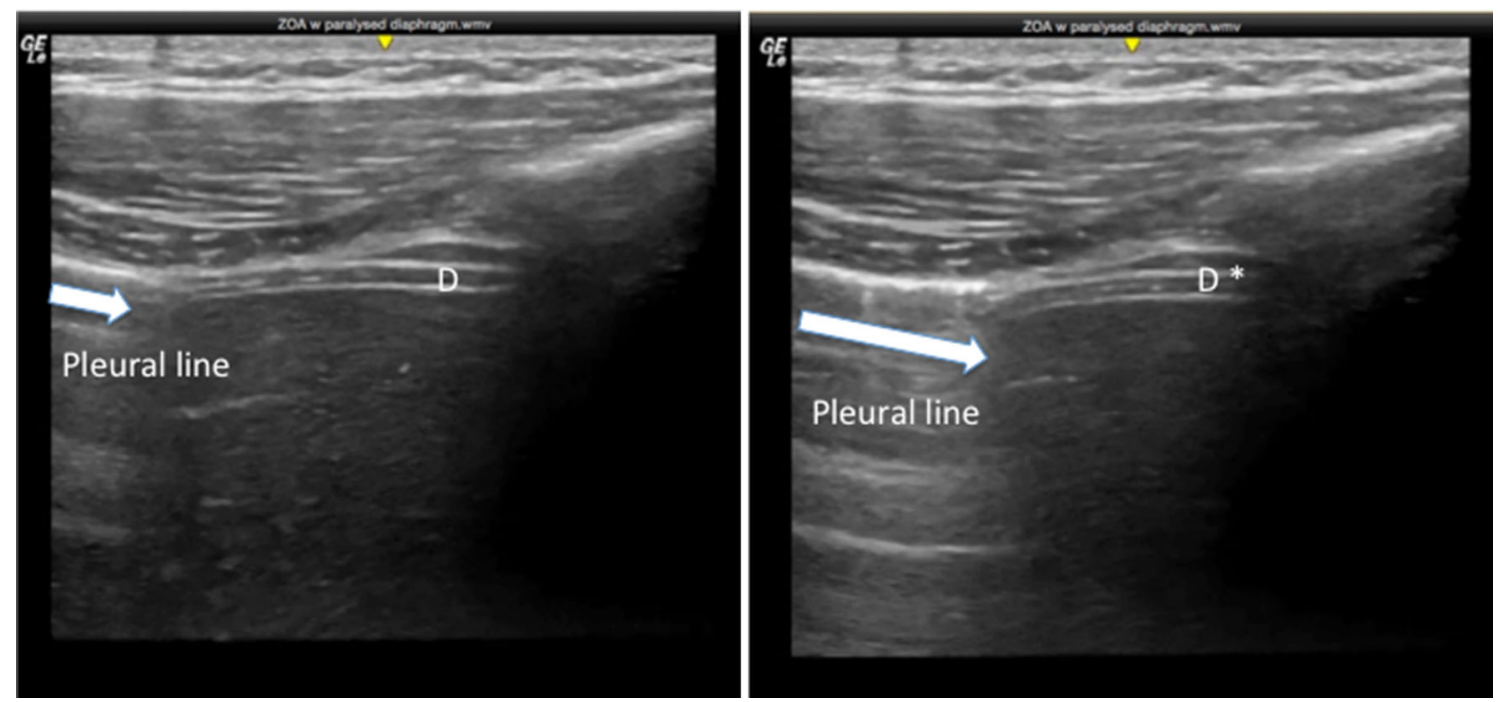

Figure Lung sliding in a patient with a paralyzed diaphragm during deep inspiration. The pleural line was clearly moving caudally although there was no appreciative diaphragmatic muscle thickening (D to $\mathrm{D}^{*}$ ). (Courtesy of Dr. Christopher Prabhakar, University of British Columbia)

visualization of lung sliding and the diaphragmatic muscle itself. Furthermore, we showed that there was no relation between changes in diaphragmatic thickness and the distance of lung sliding by surface marking. The implication of this observation is that lung sliding or pleural line movement distance recorded by surface marking cannot reliably predict diaphragm thickness changes or vice versa. Thus, cephalad or caudal displacement of the pleural reflection should serve only as an aid for locating the diaphragm, not for assessing its function.

Acknowledgement The authors greatly thank Dr. C. Prabhakar, Department of Anesthesia, University of British Columbia for sharing his experiences and expertise as well as ultrasound images on this topic.

\section{Conflicts of interest None declared.}

Editorial responsibility This submission was handled by Dr. Hilary P. Grocott, Editor-in-Chief, Canadian Journal of Anesthesia.

Funding sources None.

Other associations None.

\section{References}

1. El-Boghdadly K, Goffi A, Chan V. Point of care diaphragmatic ultrasonography made easy. Can J Anesth 2017. DOI:10.1007/ s12630-016-0766-z.

2. Naik LY, Sondekoppam RV, Tsui JJ, Tsui BC. An ultrasoundguided ABCDE approach with a sniff test to evaluate diaphragmatic function without acoustic windows. Can J Anesth 2016; 63: 1199-200.

3. Tsui JJ, Tsui BC. A novel systematic $\mathrm{ABC}$ approach to Diaphragmatic Evaluation (ABCDE). Can J Anesth 2016; 63: 636-7.

4. Sarwal A, Walker FO, Cartwright MS. Neuromuscular ultrasound for evaluation of the diaphragm. Muscle Nerve 2013; 47: 319-29.

5. Mead J. Functional significance of the area of apposition of diaphragm to rib cage [proceedings]. Am Rev Respir Dis 1979; 119(2 Pt 2): 31-2.

6. Gottesman E, McCool FD. Ultrasound evaluation of the paralyzed diaphragm. Am J Respir Crit Care Med 1997; 155: 1570-4.

7. Halliday $S$, Horne $S$, Tsui $B C$. Diaphragm thickness and its relationship to lung sliding using the abc approach to diaphragmatic evaluation: a feasibility study in patients undergoing ultrasound-guided brachial plexus blocks. Spring 2016 Abstract Titles: ASRA 41st Annual Regional Anesthesiology and Acute Pain Medicine Meeting March 31April 2, 2016 New Orleans, LA. Reg Anesth Pain Med 2016; 41: 632-52. 